\title{
Analisis dampak yang ditimbulkan akibat keberadaan tempat pemrosesan akhir (TPA) Air Sebakul Kota Bengkulu
}

\author{
M. F. Lubis ${ }^{1 *}$, Sopiah ${ }^{1}$, A. Walid ${ }^{2}$, E. P. Putra ${ }^{2}$ \\ ${ }^{1}$ Tadris Ilmu Pengetahuan Alam, IAIN Bengkulu, Bengkulu, Indonesia \\ ${ }^{2}$ Early Childhood Education, IAIN Bengkulu, Bengkulu, Indonesia
}

\begin{abstract}
Abstrak
Sampah merupakan hasil yang diakibatkan oleh adanya aktivitas kehidupan manusia, sehingga di dalam kesehariannya kita sebagai manusia masih selalu berhadapan langsung dengan yang namanya sampah. Cara pembuangan dan pemrosesan sampah yang paling banyak diterapkan di beberapa perkotaan di Indonesia termasuk Kota Bengkulu yaitu berada pada tempat pemrosesan akhir (TPA). Keberadaan TPA menimbulkan dampak terhadap lingkungan. Masalah penting untuk diselesaikan secara bersama adalah pencemaran lingkungan khususnya sampah. Tujuan penelitian ini mengetahui dampak keberadaan TPA Air Sebakul Kota Bengkulu terhadap lingkungan dan masyarakat sekitar. Penelitian ini menggunakan metode kajian kepustakaan yaitu pengumpulan berbagai kejelasan permasalahan yang relevan dengan objek penelitian. Keberadaan TPA Air Sebakul berdampak terhadap masyarakat sekitar pada beberapa aspek seperti perekonomian, kesehatan, pendidikan, lingkungan dan sosial kemasyarakatan.
\end{abstract}

Kata kunci: pencemaran lingkungan, sampah, TPA

\begin{abstract}
.
Garbage is a result caused by human work so that in our daily life as humans we are always faced with what is called garbage. Waste disposal and processing methods are most widely applied in several cities in Indonesia, including Bengkulu City, which is located at the Final Processing Site (TPA). The existence of the TPA will have an impact on the environment. The problem that is important to be resolved is about environmental pollution, especially waste. The purpose of this study was to determine the impact that occurs due to the existence of TPA Air Sebakul Bengkulu City on the environment and local communities. This research method used literature-based methods, namely research to gather a variety of clarity of the problem in accordance with the research object. The result showed that the existence of TPA Air Sebakul had an impact on surrounding community in any aspects including economy, health, education, the environment, and social communities.
\end{abstract}

Keywords: environmental pollution, rubbish, TPA

\section{PENDAHULUAN}

Sampah merupakan hasil yang diakibatkan oleh aktivitas manusia. Sampah yang berasal dari hasil kegiatan rumah tangga atau kegiatan industri, dapat mengandung zat berbahaya untuk kesehatan dan lingkungan. Sampah dapat mencemari lingkungan, merusak ekosistem dan menimbulkan bau busuk apabila tidak dikelola dengan baik (Solikhah et al. 2011). Peningkatan aktivitas manusia meningkatkan jumlah dan volume sampah. Hal inilah yang membuat pengelolaan sampah menjadi sangat penting, agar berkurang permasalahan yang dapat mencemari lingkungan (Kasam 2011).

Pengelolaan sampah memiliki banyak tahapan, mencakup sampah yang dihasilkan dari rumah tangga, industri atau pabrik; pengumpulan dan pengangkutan sampah, serta fasilitas pengelolaan sampah; sampai pada tempat pemrosesan akhir (TPA). Pencegahan untuk meminimalkan pencemaran yang ditimbulkan mesti mendapatkan perhatian serius dari pemerintah daerah. Permasalahan sampah di suatu kawasan bisa berupa cepatnya timbunan sampah

${ }^{*}$ Korespondensi Penulis

Email : mahdiyafitrilubis@gmail.com 
dan kesadaran masyarakat yang masih sangat rendah dalam membuang sampah sesuai tempatnya. Perilaku buruk masyarakat ini menyebabkan bencana banjir pada musim hujan akibat drainase yang tersumbat (Wibisono dan Dewi 2014).

Pengelolaan sampah menjadi pembicaraan sosial baik oleh masyarakat, para ahli dan pemerintah. Ketidaktepatan pengelolaan sampah dapat menimbulkan berbagai permasalahan bagi manusia berupa penyakit seperti diare, tipus dan infeksi saluran pernapasan, sedangkan bagi lingkungan seperti banjir, tanah longsor, dsb. Dampak sampah lebih banyak dihadapi oleh masyarakat di kota besar, karena merupakan tempat pertumbuhan penduduk dan lokasi tujuan migrasi (dari desa ke kota) (Kusasih dan Sumarmawati 2019).

Permasalahan terkait sampah juga terjadi di TPA Kota Bengkulu. Sampah yang masuk ke TPA di Air Sebakul, Kota Bengkulu sebanyak 260-280 ton setiap hari, berasal dari sampah rumah tangga dan pasar yang terbagi atas sampah anorganik dan organik. Dinas Lingkungan Hidup (DLH) Kota Bengkulu, setiap hari mengerahkan 28 mobil tangki bak sampah dan 67 motor bak sampah di 67 kelurahan di Kota Bengkulu. Kawasan TPA Air Sebakul sempat kewalahan dalam menampung sampah yang luasnya diperkirakan sekitar 3,5 ha.

Upaya meminimalkan sampah dan memaksimalkan daur ulang sampah memerlukan strategi pengelolaan sampah. Pemerintah daerah hendaknya mendorong program yang memberdayakan pengelolaan sampah, misalnya daur ulang sampah menjadi sesuatu yang bernilai ekonomis, sehingga timbunan sampah di TPA dapat dikurangi, walaupun ada keterbatasan dana dan sarana pengelolaan sampah. Salah satu daerah di Kota Bengkulu yang potensial untuk dikembangkan dalam pengelolaan sampah adalah TPA Air Sebakul (Supriyatna 2014). Tujuan penelitian ini adalah mengetahui dampak keberadaan TPA Air Sebakul Kota Bengkulu bagi lingkungan dan masyarakat sekitar. Masyarakat diharapkan akan termotivasi mencegah dampak yang timbul dari sampah, serta mempunyai kesadaran dan kepedulian terhadap lingkungan sekitar TPA.

\section{METODOLOGI}

\subsection{Lokasi penelitian}

Lokasi penelitian berada di Jalan Swadaya Kampung Bugis, RT 24 RW 04 Air Sebakul, Kelurahan Sukarami, Kecamatan Selebar, Kota Bengkulu, Provinsi Bengkulu (Gambar 1). Titik lokasi penelitian berada pada koordinat $3^{\circ} 50^{\prime} 1,19^{\prime \prime}$ LS dan $102^{\circ} 20^{\prime} 36,68^{\prime \prime}$ BT. Secara geografis, lokasi ini berbatasan dengan hutan lindung (cagar alam) di sebelah utara, Kembang Seri di sebelah timur, Air Sebakul di sebelah selatan dan berbatasan langsung dengan RT 23 Pagar Dewa di sebelah barat. Berdasarkan data Kantor Kelurahan Sukarami, wilayah TPA berbatasan langsung dengan Pagar Dewa di bagian utara, Sumur Dewa di bagian timur, Pekan Sabtu di bagian selatan dan Bumi Ayu di bagian barat. 


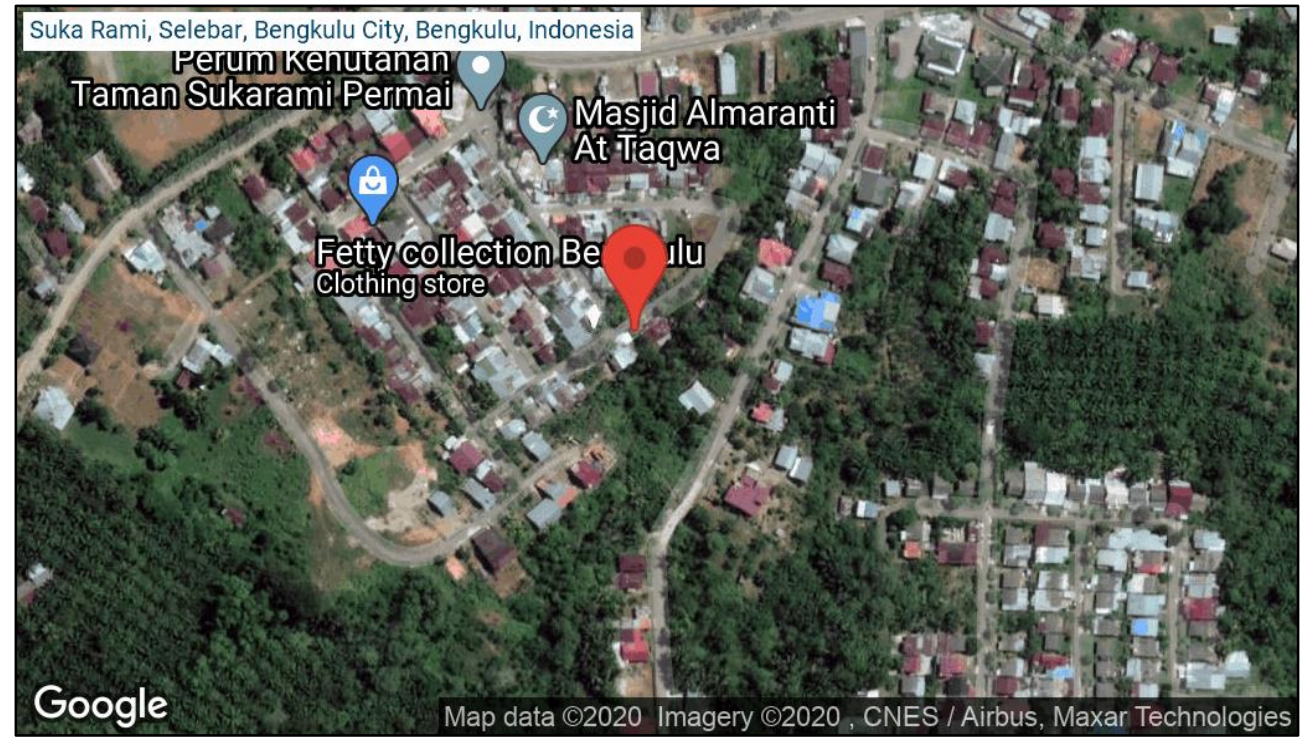

Gambar 1. Peta lokasi penelitian.

TPA Air Sebakul memiliki luas total sekitar 3 ha. Jarak lokasi TPA dengan pusat kota sekitar $15 \mathrm{~km}$, sedangkan jarak dengan pemukiman penduduk terdekat 2 atau $3 \mathrm{~km}$. Di lokasi ini juga terdapat perkebunan sawit yang merupakan salah satu mata pencaharian sebagian besar masyarakat. Bentang alam Kelurahan Sukarami berupa dataran rendah, dataran tinggi, bukit, rawa dan gambut.

\subsection{Metode pengumpulan data}

Pengumpulan data dan informasi didapatkan dari media cetak seperti buku, jurnal ilmiah dan berbagai jenis referensi lainnya seperti internet dan peraturan. Objek yang diteliti adalah TPA dan subjeknya adalah masyarakat yang tinggal di sekitar TPA. Penelitian ini merupakan jenis penelitian deskriptif dan kualitatif. Peneliti terjun langsung ke lapangan untuk mempelajari dan menganalisis, menafsirkan, serta menyimpulkan sebuah fenomena atau peristiwa di lapangan. Data yang didapat dideskripsikan untuk menemukan makna yang dijadikan sebagai hasil penelitian. Berbeda dengan halnya pada analisis kuantitatif yang mengandalkan sebuah teori, pada analisis kualitatif proses analisis dilakukan dari awal sampai akhir, karena berguna dalam memperoleh hasil analisis awal yang akan digunakan sebagai penentu pada tahap penelitian berikutnya (Poerwandari 2005). Hal yang penting dan harus dilakukan dalam menganalisis menggunakan tipe analisis apapun adalah mengawasi dan melaporkan tahapan proses selengkap dan sejujur mungkin (Patton dalam Poerwandari 2005). 


\section{HASIL DAN PEMBAHASAN \\ 3.1. Dampak keberadaan TPA}

Data dari Kantor Kelurahan Sukarami, Kecamatan Selebar, Kota Bengkulu menjelaskan bahwa TPA didirikan pada tahun 1991. Penunjukan lokasi tersebut sebagai TPA Kotamadya Daerah Tk. II Provinsi Bengkulu terdapat di dalam Surat Keputusan Wali Kotamadya Bengkulu Nomor 194 Tahun 1991. Keberadaan TPA selama 30 tahun ini memberikan dampak cukup berarti pada masyarakat sekitar, berupa pengaruh terhadap kondisi sosial masyarakat melalui berbagai aspek seperti perekonomian, kesehatan, pendidikan, lingkungan dan sosial.

\subsubsection{Aspek perekonomian}

Faktor perekonomian masyarakat di sekitar TPA semakin meningkat dan membaik, serta pengangguran berkurang. Hal ini karena masyarakat sekitar mendapat mata pencaharian baru sebagai peternak, pengepul dan pemulung (Albana 2016). Gambaran mata pencaharian masyarakat di sekitar TPA ditampilkan melalui Gambar 2.
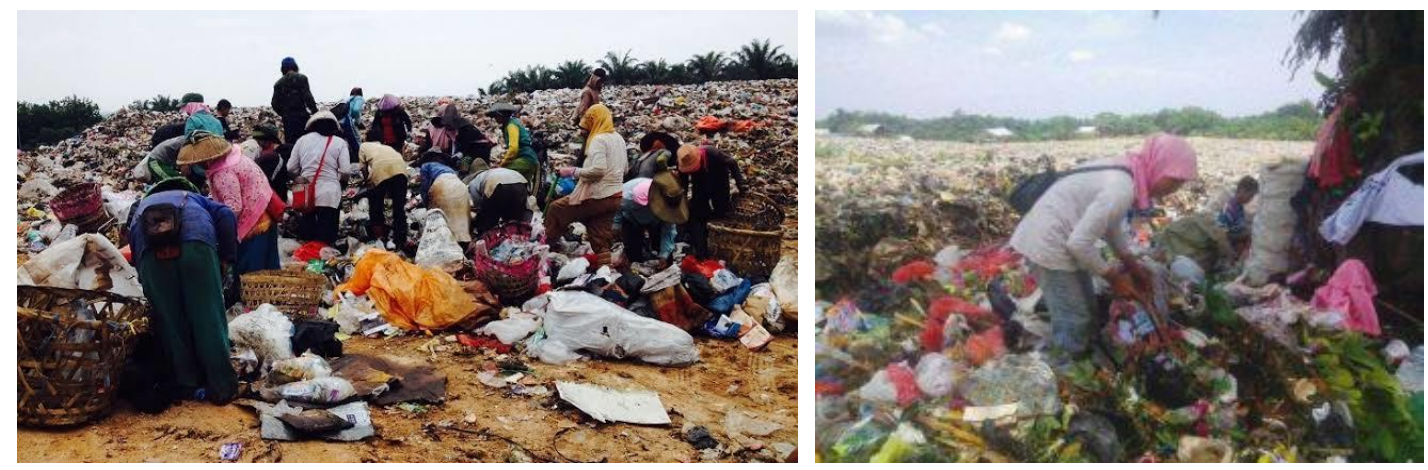

Gambar 2. Mata pencaharian masyarakat sekitar TPA.

\subsubsection{Aspek kesehatan}

Masyarakat di sekitar TPA tidak resah dengan adanya TPA di sekitar pemukiman, walaupun mereka merasa terganggu oleh bau busuk atau tidak sedap saat musim hujan. Pemantauan terhadap air dan sumur di kawasan sekitar tempat pemrosesan sampah dan pemukiman warga dilakukan rutin setiap tiga bulan sekali. Pemantauan dilakukan guna mengecek keadaan air sumur apakah terkontaminasi oleh limbah dari cairan sampah dan mengetahui kehigienisan air sumur. Sumber air masyarakat sekitar TPA berasal dari air Perusahaan Daerah Air Minum (PDAM) yang berada jauh dari TPA (Kasam 2011).

\subsubsection{Aspek pendidikan}

Kebanyakan mata pencaharian warga di sekitar TPA sebagai pemulung sampah, peternak dan petani sawit. Hal yang paling diutamakan oleh para orang 
tua adalah pendidikan anak walaupun mereka jarang mengajari anak dan pendidikan pun tidak sampai lulus SD. Walaupun begitu, demi menafkahi keluarga dan membayar biaya pendidikan anak mereka rela setiap hari mengais rezeki dengan memulung dari tumpukan sampah (Hardjasoemantri 2009).

\subsubsection{Aspek lingkungan}

Kondisi TPA Air Sebakul saat ini dalam keadaan yang sangat tidak layak dipakai, sebab sudah terlalu penuh dengan sampah yang setiap harinya masuk berkisar $300 \mathrm{~m}^{2}$. Pada saat musim hujan, truk sampah pun mengalami kesulitan untuk masuk ke blok-blok pemrosesan sampah. Perlu dilakukan penyemprotan secara berkala untuk mengatasi banyaknya lalat akibat bau busuk dari timbunan sampah. Pengelolaan sampah di TPA Air Sebakul ini sudah lebih dari 19 tahun dilakukan dengan sistem open dumping (Wijaya et al. 2013). Gambaran timbunan sampah di TPA Air Sebakul ditampilkan pada Gambar 3.

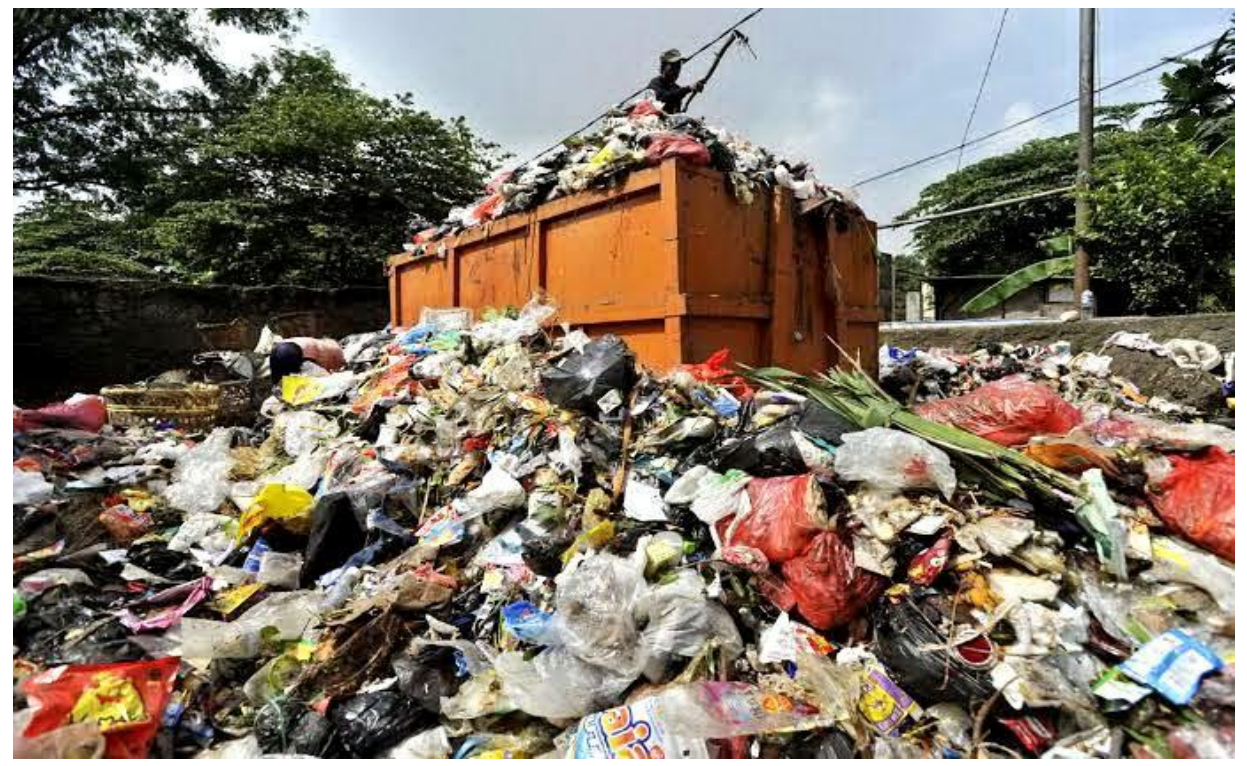

Gambar 3. Timbunan sampah bagi masyarakat sekitar TPA.

Pencemaran lingkungan akibat keberadaan TPA adalah limbah cair yang merusak sumur warga dengan zat kimianya yang berbahaya. Akses jalan di pemukiman warga yang hancur dan berlubang juga merupakan dampak lingkungan lain yang ditimbulkan, karena hampir setiap hari dilalui oleh truk yang membawa muatan sebanyak 350-400 ton sampah atau kurang lebih 160 truk. Selain dapat mengganggu lingkungan, TPA tersebut adalah penyumbang $10 \%$ sampah yang tidak termanfaatkan (Hardjasoemantri 2009). Sampah yang menumpuk di TPA tentu sangat berpengaruh terhadap lingkungan sekitar TPA, karena dapat menjadi sumber pencemaran lingkungan dan sumber penyakit. 
a. Sumber pencemaran lingkungan

Penyebab pencemaran lingkungan adalah akibat dari pengelolaan sampah yang tidak dilakukan dengan baik. Hal ini mengakibatkan timbunan sampah yang berserakan, lingkungan kotor dan kumuh, pencemaran lingkungan, menyebabkan banjir dan menjadi sarang penyakit (Walid et al. 2019).

- Pencemaran udara

Bau busuk yang dikeluarkan oleh gas metana $\left(\mathrm{CH}_{4}\right)$, karbon dioksida $\left(\mathrm{CO}_{2}\right)$ dan senyawa lainnya, berasal dari sampah organik padat. Gas tersebut merupakan gas rumah kaca yang dapat menurunkan kualitas udara di wilayah di sekitar TPA dan bau busuknya dapat mengganggu pernapasan manusia (Wibisono dan Dewi 2014). Kondisi jalan masuk menuju TPA yang dipenuhi dengan sampah di sepanjang pinggir jalan disajikan pada Gambar 4.
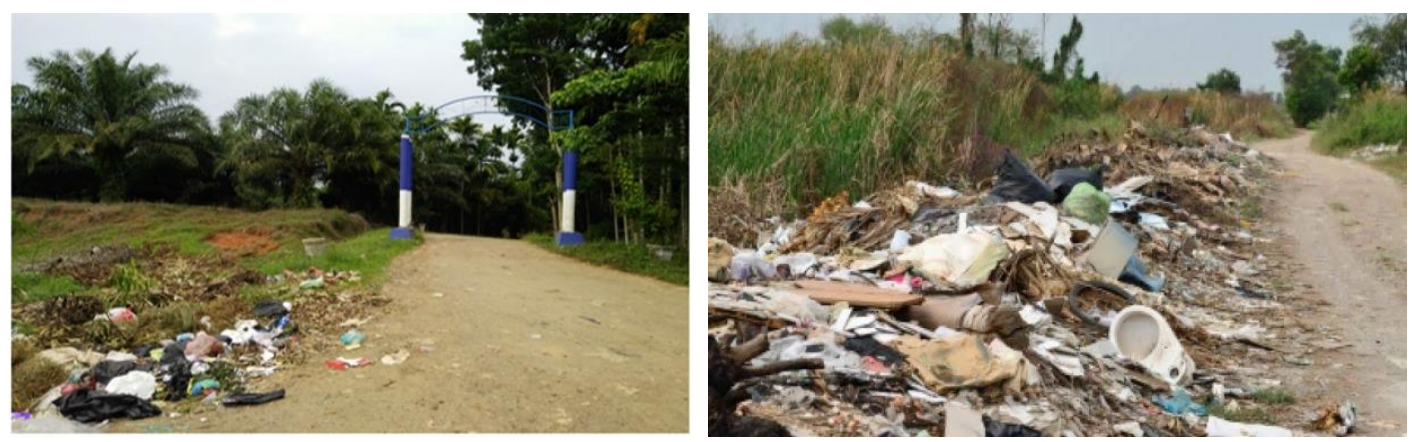

Gambar 4. Kondisi jalan masuk menuju TPA.

\section{- Pencemaran air}

Sampah yang menumpuk dan digenangi air hujan dapat mencemari air di pemukiman warga, baik air permukaan maupun air tanah. Pencemaran air berawal dari sampah yang mengandung zat kimia dari limbah pabrik yang membuat air berbau, berwarna dan tidak layak digunakan. Akibat hal ini, sumber air masyarakat setempat menjadi terkontaminasi, masyarakat mengalami kekurangan sumber air bersih dan rentan terhadap penurunan kesehatan. Air tanah yang terganggu atau tercemar dapat membahayakan manusia khususnya masyarakat yang tinggal di sekitar TPA (Wibisono dan Dewi 2014).

- Penyebab banjir

Sampah dan banjir sudah menjadi suatu fenomena yang kerap terjadi, hal ini karena sampah berbentuk padat atau keras baik segar maupun sudah busuk apabila masuk ke selokan, got, atau sungai akan membuat aliran air terhambat dan terjadi pendangkalan. Sungai dangkal akan membuat debit air berkurang, sehingga air meluap dan mengakibatkan banjir. Ketika hujan, kerap kali terjadi banjir dan menimbulkan aroma yang tak sedap. Keresahan juga akan dirasakan warga setempat karena munculnya berbagai penyakit. 


\section{b. Sumber penyakit}

Pengelolaan sampah yang tidak baik di TPA dapat menjadi sumber penyakit, baik secara langsung maupun tak langsung. Secara langsung dapat menjadi tempat berkembangnya berbagai jenis parasit, sedangkan secara tak langsung dapat menjadi sarang berbagai hewan pembawa penyakit. Berbagai penyakit yang dapat timbul diantaranya diare, cacingan, malaria, disentri dan demam berdarah. Masyarakat sekitar TPA merasakan hal tersebut dan menyatakan resah dengan semakin banyaknya lalat di dekat perkampungan akibat dekatnya lokasi keberadaan TPA dengan tempat tinggal.

\subsubsection{Aspek sosial masyarakat}

Kegiatan sosial masyarakat sekitar TPA Air Sebakul berjalan rukun dan baik seperti arisan warga sekitar TPA dan pemulung, serta gotong royong atau kerja bakti dari semua masyarakat. Pada interaksi sosial kemasyarakatan, tidak ada yang saling membeda-bedakan status pekerjaan antara pemulung dengan pekerja lainnya. Hanya sebagian kecil masyarakat saja yang memiliki hubungan kurang harmonis dengan kepala kelurahan sekitar (Ahmizal 2012).

\subsection{Pengelolaan sampah Kota Bengkulu}

Pengelolaan sampah di lingkungan Kota Bengkulu meliputi berbagai aspek yaitu aspek organisasi, hukum, penanggungan biaya, peran serta masyarakat, serta sarana dan prasarana.

\subsubsection{Aspek badan instansi/organisasi terkait}

Dinas Pertamanan dan Kebersihan atau biasa disebut Dinas Lingkungan Hidup (DLH) Kota Bengkulu adalah sebuah instansi/lembaga yang mengelola sampah. Sementara yang bertanggung jawab dalam pengoperasian dalam pengelolaan sampah adalah badan pelaksana pada teknis dinas pertamanan kota Bengkulu yang memiliki peranan utama dalam memelihara dan menjaga kebersihan taman. Ada tiga kepala yang mengetuai masing-masing seksi dan enam belas staf pekerja yang berada di bawah bidang pengawasan keindahan dan kebersihan lingkungan (Ahmizal 2012).

\subsubsection{Aspek dalam hukum}

Beberapa Peraturan Daerah terkait pengelolaan sampah sebagai upaya pelayanan pemerintah terhadap masyarakat di bidang kebersihan, yaitu:

1) Pengelolaan sampah di lingkungan Kota Bengkulu dijelaskan di dalam PerDa Kota Bengkulu Nomor 2 Tahun 2011.

2) Retribusi dalam pengelolaan sampah dijelaskan dalam PerDa Kota Bengkulu Nomor 5 Tahun 2011.

3) Pembentukan badan lembaga/organisasi dan aturan kerja DLH Kota Bengkulu dijelaskan dalam PerDa Kota Bengkulu Nomor 9 Tahun 2008. 
Peraturan tersebut mencantumkan cara pengelolaan, instansi/lembaga dana dan sanksi/hukuman yang diberikan bagi yang melanggar peraturan kebersihan. Sebagai contoh, larangan membuang sampah tidak pada tempatnya termuat di dalam PerDa Kota Bengkulu Nomor 2 tahun 2011 pada Bab VII pasal tiga empat (34). Namun, yang disayangkan adalah pelaksanaan aturan tersebut, belum pernah ada hukuman kepada yang melanggar kebersihan lingkungan. Hal ini karena belum diatur hukuman bagi yang melanggar (Ahmizal 2012).

\subsubsection{Aspek penanggungan biaya}

Pemerintah Kota Bengkulu melalui DLH Kota Bengkulu membebankan penanggung biaya dalam pengelolaan sampah di Kota Bengkulu. Peraturan itu berfungsi untuk membiayai operasional dalam pengelolaan sampah mulai dari sumber asal sampah, pengumpulan, pengangkutan, pemrosesan sampah pada tahap akhir. Diharapkan sistem pengelolaan sampah dapat dipenuhi dari pajak. Selama ini pengelolaan sampah memerlukan subsidi/biaya yang cukup besar. Pembiayaan sistem pengelolaan sampah di Kota Bengkulu ditujukan supaya bisa berjalan lancar (Pahlawati et al. 2019). Seperti yang termuat di PerDa Kota Bengkulu Nomor 2 tahun 2011 bab IV pasal 28 dan 29 bahwa Penanggung/Pembiayaan dalam menangani sampah berasal dari anggaran pendapatan dan belanja daerah (APBD) (Sari 2013).

Pada Standar Nasional Tata Cara Teknik Operasional dijelaskan terdapat biaya berupa pendanaan meliputi material untuk kompos, peralatan pembangunan serta pendanaan dalam pemasokan suplai dan memperbaiki infrastruktur pengelolaan sampah perkotaan dan sampah pemukiman. Biaya operasional sampah di Kota Bengkulu mencapai lebih dari seratus juta setiap bulannya yang meliputi pendanaan pengangkutan sampah, gaji bagi pekerja dan biaya bahan bakar kendaraan. Informasi ini langsung diperoleh dari kepala bidang kebersihan dan lingkungan Hidup Kota Bengkulu. Jumlah tersebut meliputi pendanaan dalam mengangkut sampah, upah petugas dan bahan bakar. Pemerintah Kota Bengkulu wajib membiayai penyelenggaraan pengelolaan sampah dari anggaran pendapatan dan belanja negara (APBN) serta anggaran pendapatan dan belanja daerah (APBD) seperti yang tertera dalam UU Nomor 18 Tahun 2008 tentang pengelolaan sampah.

Pemerintah Kota Bengkulu juga melakukan pungutan pajak kebersihan yang ditagih oleh Dinas Kebersihan dan Lingkungan Hidup Kota Bengkulu sebagai unit pelaksana yang bertugas dalam pengelolaan sampah di Kota Bengkulu. Surat untuk melakukan tagihan pajak dan sanksi membayar denda sebagai Surat Tagihan Retribusi Daerah (STRD). Berdasarkan PerDa Kota Bengkulu Nomor 5 Tahun 2011, pajak/retribusi dikenakan pada beberapa kawasan seperti area khusus, area industri, area komersial dan berbagai fasilitas umum. 


\subsubsection{Aspek peran serta masyarakat}

Keterlibatan masyarakat dalam menangani atau memproses sampah diantaranya seperti ikut dalam kegiatan kebersihan, rutin membayar pajak dan sumbangan persampahan di kelurahan masing-masing, bergotong royong dalam membersihkan fasilitas permukiman sekitar dan menyediakan tempat sampah di setiap halaman rumah (Artiningsih 2008). Bentuk peran serta masyarakat dalam mengelola sampah dan membangun desa ditunjukkan pada Gambar 5.

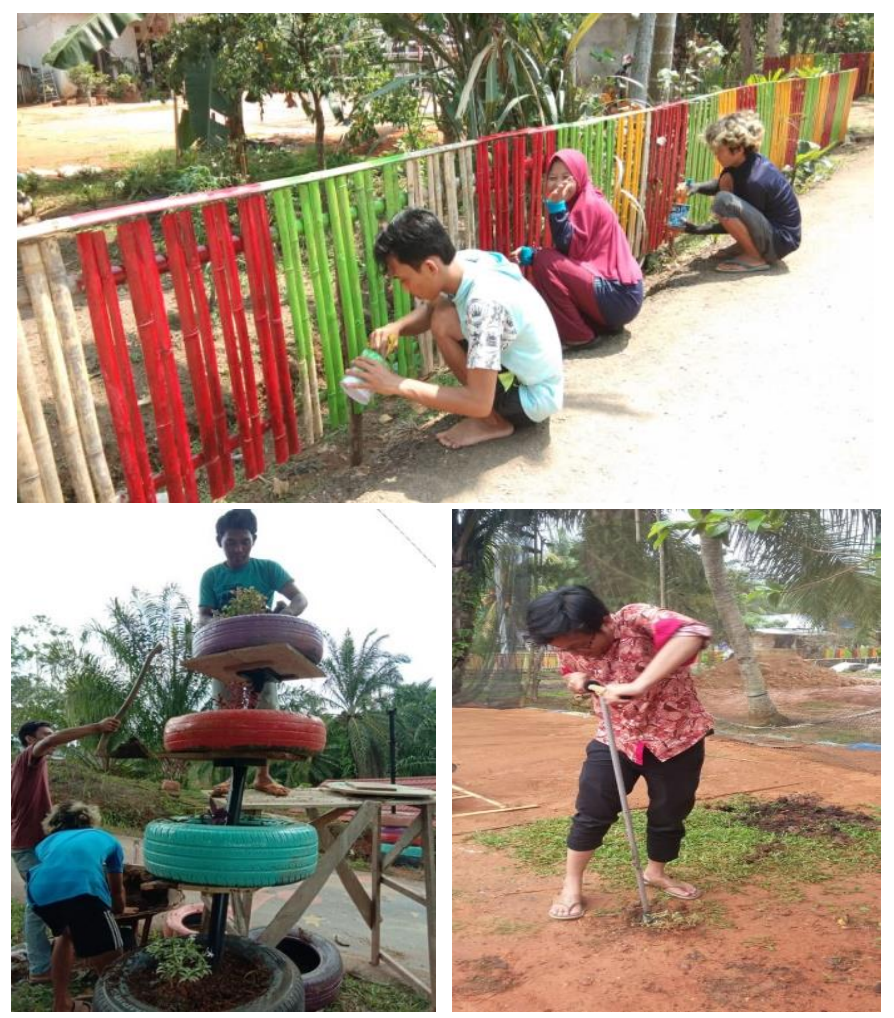

Gambar 5. Bentuk peran serta masyarakat dalam mengelola dan menangani sampah di perkampungan sekitar TPA Air Sebakul.

Pihak pemangku yang bertanggung jawab dan terlibat dalam mengelola langsung sampah adalah pemerintah daerah, masyarakat umum, pihak perusahaan swasta dan akademisi. Sesuai dengan fungsi dan perannya masingmasing, penanggung jawab berinteraksi dan berkomunikasi satu sama lain. Pemerintah bisa berperan sebagai pemberi fasilitas, masyarakat berperan langsung, perusahaan swasta bisa membantu pendanaan dan seseorang yang memiliki keahlian dan kecakapan akademik dapat berperan dalam perencanaan (Sari 2013). Kedudukan dinas untuk membina dan mengawasi pengelolaan sampah adalah melalui berbagai kegiatan penyuluhan dan pembinaan teknis pengelolaan jenis sampah. 


\subsubsection{Aspek sarana dan prasarana}

Tong sampah yang terbuat dari besi dan berbahan lunak (plastik), bakul yang terbuat dari kayu rotan, sepasang bata yang berwarna merah dan lubang untuk menimbun yang dibuat pada tanah galian adalah tempat pembuangan sampah yang dipakai sebagai tempat menampung berbagai macam sampah dari berbagai kelurahan di Kota Bengkulu. Umumnya masyarakat menggunakan bahan dari plastik khususnya pada daerah perumahan, ruko dan pertokoan. Upaya mengurangi penggunaan kantong plastik yang berlebihan adalah dengan menggunakan secara efektif wadah penampungan dari tong dan pembuatan lubang tanah/penimbunan (Adiprasetyo et al. 2019).

Secara umum, sarana yang digunakan untuk pengumpulan sampah telah memenuhi persyaratan dalam pengoperasian sampah dan memudahkan petugas melakukan pengumpulan sampah ke dalam alat pengangkutan sampah berupa gerobak sampah berkapasitas rata-rata $5 \mathrm{~m}^{3}$. Untuk saat ini belum ada tempat pemisahan sampah kering dan sampah basah (Supriyatna 2014).

\section{KESIMPULAN DAN SARAN}

\subsection{Kesimpulan}

Dampak yang ditimbulkan oleh keberadaan TPA adalah perekonomian masyarakat yang semakin meningkat dan membaik, serta dapat mengurangi pengangguran karena masyarakat sekitar mendapat mata pencaharian baru sebagai peternak, pengepul dan pemulung. Masyarakat di sekitar TPA tidak meresahkan adanya keberadaan TPA di sekitar pemukiman, walaupun mereka merasa terganggu oleh bau busuk ketika musim hujan. Pendidikan merupakan hal yang diutamakan masyarakat bagi anak-anaknya, namun demikian kurang dalam memberikan perhatian pendidikan akibat kesibukan pekerjaan.

Dampak keberadaan TPA mencemari sumur-sumur warga dan mengakibatkan akses jalan hancur atau berlubang karena dilalui truk dalam jumlah banyak setiap hari. Keberadaan TPA juga berdampak pada hubungan sosial antar masyarakat sekitar TPA yang berjalan lancar, seperti adanya kegiatan arisan dan tolong menolong antar warga yang juga berjalan dengan baik pada semua masyarakat sekitar TPA.

\subsection{Saran}

Saran terhadap pemerintah adalah agar mereklamasi TPA. Saran bagi masyarakat yang berada di sekitar TPA, agar keluar dari pekerjaan pemulung dan tidak memfokuskan mata pencaharian di tempat seperti itu, serta dapat pula memanfaatkan limbah tersebut agar memiliki nilai ekonomis. 


\section{DAFTAR PUSTAKA}

Adiprasetyo T, Hermawan B dan Herman W. 2019. Sosialisasi pengelolaan sampah organik di Kelurahan Beringin Raya, Muara Bangkahulu, Kota Bengkulu. Jurnal Pengabdian Kepada Masyarakat Dewantara 2(2):22-27. Ahmizal. 2012. Evaluasi sistem pengelolaan sampah di Kota Bengkulu [Tesis]. Universitas Bengkulu. Bengkulu

Albana B. 2016. Kontribusi wanita dalam mendukung perekonomian keluarga (studi pada pemulung di TPA Air Sebakul) [Skripsi]. Program Studi Ekonomi Syariah, Jurusan Ekonomi Islam, Fakultas Ekonomi dan Bisnis Islam, Institut Agama Islam Negeri Bengkulu. Bengkulu.

Artiningsih NKA. 2008. Peran serta masyarakat dalam pengelolaan sampah rumah tangga (studi kasus di Sampangan dan Jomblang, Kota Semarang) [Tesis]. Program Magister Ilmu Lingkungan, Program Pasca Sarjana, Universitas Diponegoro. Semarang.

Hardjasoemantri K. 2009. Hukum tata lingkungan. Gadjah Mada University Press. Yogyakarta.

Kasam. 2011. Analisis resiko lingkungan pada tempat pembuangan akhir (TPA) sampah (studi kasus: TPA Piyungan Bantul). Jurnal Sains dan Teknologi Lingkungan 3(1):19-30.

Kusasih IAKR dan Sumarmawati ED. 2019. Pemberdayaan ekonomi melalui keripik jamur tiram pada komunitas difabel di Kabupaten Klaten. Jurnal Ilmiah Pengabdian Kepada Masyarakat PAKEM 1(1):1-11.

Pahlawati S, Barchia F dan Brata B. 2019. Kajian kelayakan teknis dan lingkungan pemilihan dan penetapan TPA regional Provinsi Bengkulu. NATURALIS Jurnal Penelitian Pengelolaan Sumberdaya Alam dan Lingkungan 8(2):129133.

PerDa (Peraturan Daerah) Kota Bengkulu Nomor 9 Tahun 2008 tentang pembentukan susunan organisasi dinas daerah Kota Bengkulu.

PerDa (Peraturan Daerah) Kota Bengkulu Nomor 2 Tahun 2011 tentang pengelolaan sampah di Kota Bengkulu.

PerDa (Peraturan Daerah) Kota Bengkulu Nomor 5 Tahun 2011 tentang retribusi pelayanan persampahan di Kota Bengkulu.

Poerwandari EK. 2005. Pendekatan kualitatif dalam penelitian perilaku manusia. Lembaga Pengembangan Sarana Pengukuran dan Pendidikan Psikologi (LPSP3), Fakultas Psikologi, Universitas Indonesia. Depok.

Sari EP. 2013. Implementasi peraturan daerah nomor 2 tahun 2011 di Kota Bengkulu sebagai upaya peningkatan pengelolaan sampah [Tesis]. Program Studi Pascasarjana Ilmu Hukum, Universitas Bengkulu. Bengkulu. Solikhah NH, Hidayat AS dan Ardian AAN. 2011. Dampak keberadaan tempat pemrosesan akhir (TPA) terhadap kondisi sosial masyarakat Dusun 
Ngablak, Desa Sitimulyo, Kecamatan Piyungan, Kabupaten Bantul. Pelita 6(2):1-8.

Supriyatna EH. 2014. Evaluasi sistem pengelolaan persampahan di Kota Bengkulu [Tesis]. Magister Perencanaan Pembangunan, Sekolah Pascasarjana, Universitas Bengkulu. Bengkulu.

UU (Undang-Undang) Nomor 18 Tahun 2008 tentang pengelolaan sampah.

Walid A, Novitasari N dan Wardany K. 2019. Studi morfologi koloni bakteri udara di lingkungan Fakultas Tarbiyah dan Tadris Institut Agama Islam Negeri Bengkulu. Jurnal IPA dan Pembelajaran IPA 3(1):10-14.

Wibisono AF dan Dewi P. 2014. Sosialisasi bahaya membuang sampah sembarangan dan menentukan lokasi TPA di Dusun Deles Desa Jagonayan Kecamatan Ngablak. Jurnal Inovasi dan Kewirausahaan 3(1):21-27.

Wijaya A, Alfansi L dan Benardin. 2013. Pengelolaan sampah di Kota Bengkulu. Jurnal Ekonomi dan Perencanaan Pembangunan 5(2):86-95. 